184

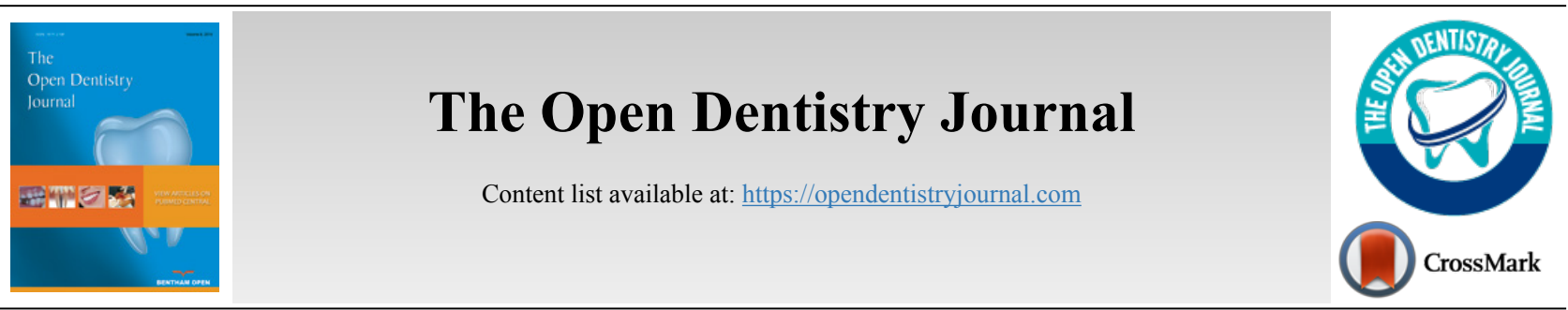

RESEARCH ARTICLE

\title{
Awareness and Practices of Dental Students and Dentists Regarding Infection Control in Prosthodontic Clinics
}

Ragheb Halawani ${ }^{1, *}$, Khalid Aboalshamat ${ }^{2}$, Ruba Alwsaidi ${ }^{3}$, Sultana Sharqawi ${ }^{3}$, Rawan Alhazmi ${ }^{4}$, Zahra Abualsaud $^{3}$, Amal Alattallah ${ }^{4}$ and Maha Alamri ${ }^{3}$

${ }^{1}$ Department of Dentistry, Umm Al-Qura University, Makkah, Saudi Arabia

${ }^{2}$ Dental Public Health Division, Preventive Dentistry Department, Faculty of Dentistry, Umm Al-Qura University, Makkah, Saudi Arabia

${ }^{3}$ Department of Dentistry, Alfarabi Private College, Jeddah, Saudi Arabia

${ }^{4}$ Department of Dentistry, King Fahad Armed Forces Hospital, Jeddah, Saudi Arabia

\begin{abstract}
:
Background:

Patient safety is a priority for achieving higher quality health care standards and human error $>$ reduction.

Objective:

The aim of this study was to evaluate the level of appropriate infection control practices in a prosthodontic clinic in Jeddah, Saudi Arabia.

Methods:

This cross-sectional study included 460 dental students and dentists recruited from five centers. Data were collected by self-administered questionnaires $>$ composed of 25 questions. The questionnaires $>$ assessed infection control practices in prosthodontic clinics, including wearable barriers, disinfection measures among patients, disinfection of laboratory submissions, and proper infection control. Other questions assessed sources of knowledge, self-evaluation of knowledge, implementation, and satisfaction with knowledge application.

Results:

Total correct answers for proper practice (16 questions) had a mean of 12.5 with a standard deviation of 2.8 . The most commonly practiced procedure was wearing a mask (99.8\%) and the least was sterilizing the facebow before its use by the patient (53.7\%). Participants from governmental colleges $(\mathrm{m}=13.67, \mathrm{SD}=2.17)$ had significantly higher scores than participants from private colleges $(\mathrm{m}=12.35, \mathrm{SD}=2.9), p$ $<0.001$. Only $2.8 \%$ had never attended a lecture, and only $13.8 \%$ had never had hands-on training for infection control. Despite $49.1 \%$ evaluating themselves as having very poor to poor knowledge, $90.7 \%$ had fair to very good valuation of their infection control implementations, and $87.6 \%$ were satisfied with their knowledge and performance levels.

\section{Conclusion:}

Dental students and dentists have high levels of adequate infection control practices in the prosthodontic clinic despite the moderate level of their satisfaction with their knowledge.
\end{abstract}

Keywords: Prosthodontic, Infection control, Saudi Arabia, Practice, Dental students, Dentists.

\begin{tabular}{l|l|l|l}
\hline Article History & Received: February 03, 2020 & Revised: March 19, 2020 & Accepted: March 30, 2020
\end{tabular}

\section{INTRODUCTION}

Assuring patient safety is one of the priorities in the process of achieving higher quality health care standards and

\footnotetext{
* Address correspondence to this author at the Department of Dentistry, Umm Al-Qura University, Makkah, Saudi Arabia;

E-mail: raghebali.ra@gmail.com
}

error reduction [1]. Infectious diseases are among the main problems jeopardizing patient safety and health care worldwide [2]. The dental environment is a hazardous one with tremendous potential to affect patients and healthcare workers with $>$ infections such as Acquired Immunodeficiency Syndrome (AIDS) and hepatitis [3 - 5]. In fact, patients' $>$ oral cavities are perfect habitats for the transmission of bacteria and 
other germs that can be infectious to others [6]. Most clinical procedures in dentistry include exposure to saliva, blood, or other contaminated and highly contagious elements [6,7]. Thus, maintaining infection control is an essential practice for dental clinics as a crucial protocol for preserving the practice's integrity.

Many studies have advocated strict adherence to infection control guidelines in dental clinics $[6,8,9]$. However, dental students and dentists in previous studies have demonstrated low levels of compliance with infection control guidelines [8 11 ], which increases the probability of cross-contamination in a possibly serious manner such as through a needle prick [11 13]. In fact, several studies have assessed the levels of knowledge, attitude, and practice of infection control by dentists and dental students in dental clinics in various countries, including Saudi Arabia [14 - 16] and Yemen [17]. These studies have generally shown variable levels of knowledge and practicesaimed at infection control; however, the authors have concluded that levels of knowledge should be improved and that practices were not satisfactory and need to be strengthened to adhere to guidelines for better infection and disease control.

One of the areas of frequent infection are the prosthetics in prosthodontic clinics and dental prosthetic labs, and this has become a growing concern frequently reported in $>$ the literature [18]. In fact, many studies have assessed different modalities for controlling infection in dental prosthetics using a variety of materials, including chlorhexidine digluconate, sodium hypochlorite, sodium perborate, sodium hypochlorite, and vinegar in different concentrations and applications [19, 20], which highlight its importance. Prosthetic clinics have a number of instruments used for various procedures that result in frequent transportation of impressionable materials between the dental clinic and the laboratory, increasing the possibility $>$ for cross-contamination $[21,22]$. This means that a number of studies have concentrated more on infection control in dental prosthetic clinics.

Two studies assessed the knowledge and practice of infection control in prosthetic clinics in India [23] and in Riyadh, Saudi Arabia [24].The studies had similar results, showing that $14.4 \%$ to $17.8 \%$ of the respondents disinfect dental casts before sending them to the laboratory, and all of them used gloves during prosthetic treatments. Students had fair to good scores in awareness of prosthetic infection control policies, and around half of the students were satisfied with their knowledge and performance. However, the results were different in terms of hazardous events, where sharp injuries and eye splashing occurred at rates of $28.9 \%$ and $18.3 \%$, respectively, in India [23], and $57 \%$ and $30.2 \%$, respectively, in Saudi Arabia [24], so the students in Saudi Arabia experienced $>$ more contagious events. In fact, the Saudi study [24] reported that students were highly concerned about wearing face masks, gloves, and protective gowns, but were less concerned about using safety glasses and protective head caps as safety barriers. There were $53.5 \%$ to $79.1 \%$ of the participants who were aware of the need to clean instruments used in prosthodontic clinics, including alginate mixing spatulas, rubber bowls, shade guides, and facebows [24], which justifies the authors' conclusion that student knowledge and practices for infection control in prosthetic clinics should be boosted.

However, the results of such studies cannot be generalized to other cities in Saudi Arabia, and therefore, because of the importance, it is necessary to assess similar topics in other Saudi cities such as Jeddah, which is considered the secondlargest city with a population of dentists and which has numerous private dental schools that might have different levels of knowledge and practice. Thus, the aim of this study was to evaluate the knowledge and practices of dental students and dentists in Jeddah, Saudi Arabia, regarding infection control in prosthodontics clinics.

\section{MATERIALS AND METHODS}

This was a multi-center cross-sectional study with the participants recruited from all of the dental colleges located in Jeddah (King Abdulaziz University, Alfarabi, Batterjee, and Ibn Sina) dental colleges, in addition to the dental department of the King Fahad Armed Forces Hospital. Data collection took place from November to December 2019. The inclusion criteria were dental students in clinical years (fourth, fifth, sixth, and intern), general dentists, or dentists who were working in a prosthetic clinic at the time of the study. Students were identified by their university identification card, and dentists were identified by their work card. Exclusion criteria were dentists who worked in areas other than prosthetics, such as public health, orthodontics, oral radiology, oral diagnosis, oral surgery, endodontics, pedodontics, and all other basic oral sciences departments. A convenience sampling technique was used, and by conducting a sample size calculation with a confidence level of $90 \%$, the estimated prevalence of $50 \%$, and precision level of $5 \%$, it was determined that the minimum number of participants required for this study was 271 . To obtain >an estimated non-response rate, 500 participants were invited to participate in this study. A hard copy selfadministered questionnaire was distributed to the target population by the research team during participants' break times at work or school, and the completed questionnaires were collected immediately after participants finished the task. The average time to complete the questionnaire was six minutes.

The questionnaire was derived from two previous studies $[23,24]$, with modifications, and it was composed of four sections. The first section had four demographic questions about gender, age, academic year or work status, and place of study or work. The second section was composed of 16 questions investigating the practice of infection control in the prosthetic clinic, including the use of gloves, face masks, eyeglasses, gowns, and head caps and the practices of disinfecting patients, disinfecting materials before sending it to the lab, disinfecting of a final impression, and sterilization of certain instruments used in prosthetic clinics. The third section consisted of two questions about the education of $>$ the participant received during their academic years of study with regard to infection control. The third and fourth sections included three questions on self $>$-evaluation of personal satisfaction with knowledge and the implementation of infection control procedures in the clinic. The statistically 
significant level was set at 0.05 , and data analysis was conducted using SPSS v21 (IBM Corp., Armonk, NY, USA).

The study was approved by the Faculty of Dentistry Institutional Review Board, Umm Al-Qura University, with ethical approval number 151-19. All the participants signed the study consent before participating after being advised that participation in the study was entirely voluntary and that all data were anonymous to protect participants' confidentiality.

Table 1. Demographic data of participants.

\begin{tabular}{|c|c|c|c|}
\hline Variables & & Frequency & Percent \\
\hline Gender & Male & 178 & $38.7 \%$ \\
\hline & Female & 282 & $61.3 \%$ \\
\hline Academic/ working level & $4^{\text {th }}$ year student & 27 & $5.9 \%$ \\
\hline & $5^{\text {th }}$ year student & 136 & $29.6 \%$ \\
\hline & $6^{\text {th }}$ year student & 153 & $33.3 \%$ \\
\hline & Intern & 87 & $18.9 \%$ \\
\hline & General practitioner & 41 & $8.9 \%$ \\
\hline & Post grad student & 8 & $1.7 \%$ \\
\hline University/ hospital & Specialist/consultant & 8 & $1.7 \%$ \\
\hline & Private & 393 & $85.4 \%$ \\
\hline & Governmental & 67 & $14.6 \%$ \\
\hline
\end{tabular}

\section{RESULTS}

A total of 460 of 500 invited dentists and dental students participated in this study, making a response rate of $92 \%$. The mean age was 25.01 , with a standard deviation (SD) of 3.03 . There were $316(68.70 \%)$ students and 144 (31.3\%) interns or graduated dentists. The participants' $>$ demographic data are displayed in Table $\mathbf{1 .}$
Participants' answers to the items regarding infection control practices are shown in Table $\mathbf{2}$. Bearing $>$ in mind that 'Yes' was the correct choice for all questions. After calculating the total correct answers for these 16 questions, the mean of correct answers was calculated as 12.5 with SD of 2.8 . The ttest showed that participants from governmental colleges $(\mathrm{m}=$ 13.67, $\mathrm{SD}=2.17$ ) had significantly higher scores than participants from private colleges $(\mathrm{m}=12.35, \mathrm{SD}=2.9), \mathrm{t}(458)$ $=3.549, p<0.001$. However, the $\mathrm{t}$-test and linear regression showed that the total correct practice score was not significantly related to age, gender, or academic/working level. In $>$ Kruskal-Wallis test, to compare 4th, 5th, and 6th year students, dental internees $>$, and graduated dentists, there was no significant difference in the total knowledge score regarding infection control in prosthetic clinics $>(\mathrm{H}(4)=8.216, \mathrm{p}=0.084)$.

Participants had varied experiences regarding theoretical lectures about infection control during their academic studies, where $2.8 \%$ had never attended a lecture, $46.3 \%$ had few lectures during their undergraduate studies, $22 \%$ had one weekly lecture during an academic semester, $15.4 \%$ had one weekly lecture during an academic year, and $13.5 \%$ had more lectures than all of the others. Regarding hands-on infection control training, 13.9\% had never attended a workshop, $45.4 \%$ attended one workshop during their undergraduate program, $25.9 \%$ attended two workshops during their undergraduate program, and $14.8 \%$ attended a workshop every year.

Participants were asked to self-evaluate their knowledge levels, their implementation of infection control measures, and their satisfaction with their knowledge of infection control measures in prosthetic clinics. The participants' answers are shown in Table 3.

Table 2. Participant answers regarding correct infection control practices in dental prosthetic clinics.

\begin{tabular}{|c|c|c|c|}
\hline Situation & Item & $\begin{array}{l}\text { Yes* } \\
n(\%)\end{array}$ & $\begin{array}{c}\text { No } \\
n(\%)\end{array}$ \\
\hline \multirow[t]{5}{*}{$\begin{array}{l}\text { Wear barriers during clinical procedures in } \\
\text { prosthodontic clinic } \\
\end{array}$} & Gloves & $459(99.8 \%)$ & $1(0.2 \%)$ \\
\hline & Face mask & $432(93.9 \%)$ & $28(6.1 \%)$ \\
\hline & Protective gowns & $451(98 \%)$ & $9(2 \%)$ \\
\hline & Protective eyeglasses & $279(60.7 \%)$ & $181(39.3 \%)$ \\
\hline & Head cap & $275(59.8 \%)$ & $185(40.2)$ \\
\hline \multirow[t]{3}{*}{ Disinfecting items between patients } & Rubber bowl & $377(82 \%)$ & $83(18 \%)$ \\
\hline & Alginate mixing spatula Facebow & $381(82.8 \%)$ & $79(17.2 \%)$ \\
\hline & Shade guide & $365(79.3 \%)$ & $95(20.7 \%)$ \\
\hline \multirow[t]{3}{*}{$\begin{array}{l}\text { Disinfecting items before sending to dental } \\
\text { laboratory }\end{array}$} & Dental cast & $371(80.7 \%)$ & $89(19.3 \%)$ \\
\hline & $\begin{array}{c}\text { Metal framework for removable or fixed prosthesis after trying in bite } \\
\text { registration }\end{array}$ & $380(82.6 \%)$ & $80(17.4 \%)$ \\
\hline & Facebow and fork & $307(66.7 \%)$ & $153(33.3 \%)$ \\
\hline \multirow[t]{2}{*}{$\begin{array}{l}\text { Infection control measures for primary or final } \\
\text { impression }\end{array}$} & $\begin{array}{c}\text { Rinse the impression under running water immediately after being } \\
\text { removed from the patient's mouth }\end{array}$ & $422(91.7 \%)$ & $38(8.3 \%)$ \\
\hline & Apply a disinfectant to impression after being rinsed with water & $422(91.7 \%)$ & $38(8.3 \%)$ \\
\hline \multirow[t]{3}{*}{$\begin{array}{c}\text { Sterilize (or autoclave) items before being used } \\
\text { with patient }\end{array}$} & Impression trays & $350(76.1 \%)$ & $110(23.9 \%)$ \\
\hline & Facebow & $247(53.7 \%)$ & $213(46.3 \%)$ \\
\hline & Fork for occlusal plane & $253(55 \%)$ & $207(45 \%)$ \\
\hline
\end{tabular}

\footnotetext{
*(Yes) was the correct choice for all items.
} 
Table 3. Participant self-evaluation of knowledge, implementation, and satisfaction about knowledge and performance regarding infection control in a prosthetic clinic.

\begin{tabular}{|c|c|c|c|c|c|}
\hline Knowledge Level & $\mathbf{\%}$ & Implementation & $\mathbf{\%}$ & Satisfaction with Knowledge and Performance & $\mathbf{\%}$ \\
\hline Very poor & 2.8 & Very poor & 6.1 & Not satisfied & 1.7 \\
\hline Poor & 46.3 & poor & 3.2 & Somewhat satisfied & 10.7 \\
\hline Fair & 22.0 & Fair & 15.0 & Fairly satisfied & 22.8 \\
\hline Good & 15.4 & Good & 50.7 & Nearly satisfied & 40.7 \\
\hline Very good & 13.5 & Very good & 25.0 & Totally satisfied & 24.1 \\
\hline
\end{tabular}

\section{DISCUSSION}

This study aimed to evaluate the level of appropriate infection control practices by students and dentists in university dental prosthetic clinics in Jeddah, Saudi Arabia. Generally, participants showed high levels of awareness and implementation of most of the correct infection control procedures. Nevertheless, some infection control procedures that were not followed by the majority were wearing head caps, using protective eyeglasses, disinfecting the facebow and bite forks before sending materials to the lab and sterilizing certain items before using them on patients, including facebow and bite fork for Fox's occlusal plane plate. Very few participants had not attended any previous lectures or workshops about infection control. Despite half of the participants rating themselves as having poor knowledge, around three-fourths were fairly to totally satisfied with their level of knowledge and also believed they were fairly good to very good about implementing infection control procedures in prosthetic clinics fairly to very good.

Assessing infection control in a prosthetic clinic is a very important issue because of the risks involved in $>$ working with several procedures and material exchanges between dentists, patients, and the laboratory, with tremendous potential for cross-contamination among them, as highlighted by the Korean Society of Prosthodontic Review [21] and a recent systematic review [22]. This might be more important than contamination by sharp injuries, which were found to have a lower rate of incidence in comparison to other dental specialties [25].

Comparing our results with previous studies reveals some similarities and some differences. Two major studies were similar in assessing infection control practices in prosthetic clinics in India among private dental colleges [23] and in Riyadh, Saudi Arabia, among governmental dental colleges [24]. However, our study involved four dental colleges where some were private and some were governmental, so it had more variability. Despite the expectation that senior $>$ dental students should be more knowledgeable about infection control, our results indicated no significant difference> between the students, dental intern or graduated dentists (specialists/ consultants). This might be the result of the low number of participants in 4th year students or graduated dentists. Future studies are needed to confirm with a larger sample size of graduated dentists.

While comparing the results regarding wearing barriers, in our study, almost all of the participants wore gloves and face masks, ranging from $93.9 \%$ to $99.8 \%$, which was similar to the Indian and Riyadh studies previously mentioned [23, 24].
However, there was variability in the percentage of participants wearing gowns, protective eyeglasses, and head caps. In our study, gowns, protective eyeglasses, and head caps were used by $98 \%, 60.7 \%$, and $73.3 \%$ of the participants, while in the Riyadh study, 96\%, 73.3\%, and 36\% [24], and in the Indian study, $21.1 \%, 37.2 \%$, and $96.6 \%$ [23] of the participants, respectively. This might indicate that different universities in different cities enforce different infection control rules and regulations. In fact, such relatively lower compliance with wearing eyeglasses and head caps was noticed in other studies assessing dental practitioners in clinics among local [26] and non-local studies [27]. However, it should be mentioned that around $30.2 \%$ of dental students and dentists were affected by eye splash injuries in prosthetic clinics [24], which urges stakeholders to enforce the wearing of proactive barriers of different types and not only gloves and face masks.

Infections can also spread from patient to patient if materials are not disinfected. Disinfecting such tools is very important; for example, shade guides should be cleaned and to be disinfected using an intermediate level hospital tuberculocidal disinfectant, according to Occupational Safety and Health Administration (OSHA) guidelines [28]. Our data showed that the disinfection of rubber bowls, mixing spatulas, and shade guides ranged from $79.3 \%$ to $82.8 \%$, which was greater than the studies from Riyadh $(53.5 \%$ to $60.5 \%)$ [24] and India $(56.1 \%$ to $62.2 \%$ ) [23]. Conversely, the rate of instrument sterilization using an autoclave for impression trays, facebows, and the bite fork of Fox's occlusal plane plate ranged in our study between $53.7 \%$ and $76.1 \%$, which was lower than the Riyadh study $(73.3 \%$ to $84.9 \%)$ and the Indian study $(57.2 \%$ to $87.2 \%)$ for the same items. Here again, the difference might be attributable to the variability in compliance with infection control guidelines of different universities and cities in Saudi Arabia. It is recommended that future studies assess the policies of the universities and dental clinics to understand if such practices are based on dental students and dentists' own knowledge or are following the organizational guidelines.

Because numerous studies have highlighted the potential for cross-infection when using and transferring materials between dental clinics and laboratories, the Centers for Disease Control (CDC) recommended that dental practitioners disinfect all impressions, dental casts, metal framework, bite registrations or wax before sending them to the dental laboratory [6]. Our study showed that the percentage of participants who disinfected dental casts, prostheses, metal frameworks, facebows, and the bite fork of the occlusal plane plate ranged from $66.7 \%$ to $82.6 \%$, which was a little higher 
than the Riyadh study (62.6\% to 68.6$)$ [24], but similar to the Indian study (54.4\% to $87.2 \%$ ) [23]. It should be noted that rates of disinfection of the facebow and bite fork of Fox's occlusal plane plate were the lowest in all three studies. This may be because students, in general, might have problems using the facebow; some studies have implied that the use of a facebow is not taught in all dental colleges [29].

Furthermore, and more importantly, our results and the two other studies $[23,24]$ showed that the majority of participants do rinse impressions with running water before sending them to the laboratory; however, while our study and the Riyadh study showed that the majority of the participants also disinfected them after using the water, the Indian study did not show this $>$ result.

Similar to other studies, only a small percentage of the participants did not attended $>$ any theoretical lectures about infection control. This is similar to previous studies [23, 24]. However, there were $13.9 \%$ who had never attended any practical training for infection control, which was lower than that reported in previous studies $(39.5 \%-40.6 \%)[23,24]$. This might indicate that dental colleges in Jeddah had better coverage of this topic in continuing education workshops. Indeed, attendance at such lectures and workshops on an annual basis has $>$ a relationship with $>$ increased levels of compliance and awareness about infection control.

Self-evaluation is considered to be key for understanding participants' future attitudes toward infection control in the prosthodontic clinic. Around $50 \%$ of the students rated their knowledge level as very poor or poor despite having good knowledge scores. Yet at the same time, the majority evaluated their implementations as fair to very good and were also satisfied with their levels of knowledge and performance. When comparing this to previous studies [23, 24], this contradiction exists only with regard to self-evaluation of levels of knowledge. Previous studies have had low numbers of participants who rated themselves as having poor knowledge level $(3.5 \%$ to $3.9 \%)$. This might indicate that participants in Jeddah underestimate their levels of knowledge and have low self-confidence in their knowledge for unknown reasons. One explanation is that participants might think there are areas they do not know or procedures they are not sure about. Selfconfidence is usually associated with good clinical practice in dentistry $[30,31]$, so this point can be covered for future infection control continuing education in the future.

An important aspect of this study is investigating some practices that occur only in prosthetic clinics, such as the use of a facebow, whereas other studies about infection control have focused on general dentistry practices $[32,33]$ and do not focus on such areas. In addition, this study was conducted using four dental colleges that were both private and governmental, in addition to one major governmental hospital, so it had more representative data in comparison to similar studies. In fact, our data also showed that there might be some differences in practices; our results indicated that governmental organizations seem to better adhere to infection control practices. Such comparison had not been conducted in prior similar studies where the data were taken from a single center. The study does have a few limitations worth mentioning. The number and distribution of participants were $>$ not representative of all of Saudi Arabia, and thus our results lack external validity. Also, the questionnaire did not include lab technicians, who play an important $>$ role in infection control at prosthodontic clinics. More studies are needed to >investigate the policies at other dental colleges in order to make better recommendations to all stakeholders. Furthermore, future studies might investigate infection control precaution awareness toward the Middle East Respiratory Syndrome (MERS), Severe Acute Respiratory Syndrome (SARS) and coronavirus (COVID-19) in the light of recent pandemic occurring $>$ in the world [34] that has $>$ even reached Saudi Arabia.

\section{CONCLUSION}

Our results indicated that dental students and dentists have high levels of knowledge regarding $>$ appropriate practices for infection control in prosthodontic clinics. Few participants had not received any previous lectures or workshops about infection control. Moreover, despite half of the participants rating themselves as having poor knowledge, around threefourths were fairly to totally satisfied with their levels of knowledge and also believed they were fairly good to very good at implementing infection control procedures. Our data were generally similar to previous local and international studies, with some variations that can be attributed to differences in policies and culture between universities. Future studies can be implemented with more generalized samples from Saudi universities, and it is recommended to investigate organizational policies to understand their effects on dental students and dentists in terms of compliance with infection control guidelines in prosthetic clinics.

\section{ETHICS APPROVAL AND CONSENT TO PARTI- CIPATE}

This study received the approval of the Institutional Review Board, Umm Al-Qura University, Saudi Arabia, with ethical approval number 151-19.

\section{HUMAN AND ANIMAL RIGHTS}

No animals were used in this research. All human research procedures followed were in accordance with the ethical standards of the committee responsible for human experimentation (institutional and national), and with the Helsinki Declaration of 1975, as revised in 2013.

\section{CONSENT FOR PUBLICATION}

All participants signed the consent before participating in the study.

\section{AVAILABILITY OF DATA AND MATERIALS}

The data that support the findings of this study are available from the corresponding author, $[\mathrm{RH}]$, upon reasonable request.

\section{FUNDING}

None. 


\section{CONFLICT OF INTEREST}

The authors declare no conflict of interest, financial or otherwise.

\section{ACKNOWLEDGEMENTS}

We thanks the participants for their time to answer the study questionnaire.

\section{REFERENCES}

[1] Yamalik N, Van Dijk W. Analysis of the attitudes and needs/demands of dental practitioners in the field of patient safety and risk management. Int Dent J 2013; 63(6): 291-7.

[http://dx.doi.org/10.1111/idj.12081] [PMID: 24716242]

[2] WHO. Ten threats to global health in 2019 [Internet]. Available from: https://www.who.int/ emergencies/ ten-threats-to-global-healthin-2019

[3] Ayatollahi J, Ayatollahi F, Ardekani AM, et al. Occupational hazards to dental staff. Dent Res J (Isfahan) 2012; 9(1): 2-7. [http://dx.doi.org/10.4103/1735-3327.92919] [PMID: 22363355]

[4] Hu T, Li G, Zuo Y, Zhou X. Risk of hepatitis B virus transmission via dental handpieces and evaluation of an anti-suction device for prevention of transmission. Infect Control Hosp Epidemiol 2007; 28(1): 80-2.

[http://dx.doi.org/10.1086/510808] [PMID: 17230392]

[5] Laheij AMGAS, Kistler JO, Belibasakis G, Välimaa H, De Soet J. European Oral Microbiology Workshop EOMW 2011. Healthcareassociated viral and bacterial infections in dentistry. J Oral Microbiol 2012; 4(10): 17659.

[http://dx.doi.org/10.3402/jom.v4i0.17659]

[6] Kohn WG, Collins AS, Cleveland JL, Harte JA, Eklund KJ, Malvitz DM. Guidelines for infection control in dental health-care settings-2003. Atlanta, GA: Centers for Disease Control and Prevention

2003.https://www.cdc.gov/mmwr/preview/mmwrhtml/rr5217a1.htm

[7] Taiwo JO, Aderinokun GA. Assessing cross infection prevention measures at the Dental Clinic, University College Hospital, Ibadan. Afr J Med Med Sci 2002; 31(3): 213-7. [PMID: 12751559]

[8] Ahmad IA, Rehan EA, Pani SC. Compliance of Saudi dental students with infection control guidelines. Int Dent J 2013; 63(4): 196-201. [http://dx.doi.org/10.1111/idj.12030] [PMID: 23879255]

[9] Cleveland JL, Bonito AJ, Corley TJ, et al. Advancing infection control in dental care settings: factors associated with dentists' implementation of guidelines from the Centers for Disease Control and Prevention. J Am Dent Assoc 2012; 143(10): 1127-38.

[http://dx.doi.org/10.14219/jada.archive.2012.0044] [PMID: 23024311]

[10] Al-Omari MA, Al-Dwairi ZN. Compliance with infection control programs in private dental clinics in Jordan. J Dent Educ 2005; 69(6): 693-8.

[PMID: 15947216]

[11] Gordon BL, Burke FJ, Bagg J, Marlborough HS, McHugh ES. Systematic review of adherence to infection control guidelines in dentistry. J Dent 2001; 29(8): 509-16.

[http://dx.doi.org/10.1016/S0300-5712(01)00043-4] [PMID: 11700199]

[12] Al-Dharrab AA, Al-Samadani KH. Assessment of hepatitis B vaccination and compliance with infection control among dentists in Saudi Arabia. Saudi Med J 2012; 33(11): 1205-10. [PMID: 23147878]

[13] Cheng HC, Su CY, Yen AM, Huang CF. Factors affecting occupational exposure to needlestick and sharps injuries among dentists in Taiwan: a nationwide survey. PLoS One 2012; 7(4)e34911 [http://dx.doi.org/10.1371/journal.pone.0034911] [PMID: 22509367]

[14] Al-Maweri SA, Tarakji B, Shugaa-Addin B, Al-Shamiri HM, Alaizari NA, AlMasri O. Infection control: Knowledge and compliance among Saudi undergraduate dental students. GMS Hyg Infect Control 2015; 10: Doc 10.

[PMID: 26199855]

[15] Assiri KI. Naheeda, Kaleem SM, Ibrahim M, Alam T, Asif SM. Knowledge, attitude, and practice of infection control among dental students in King Khalid University, Abha. J Int Oral Health 2018; 10(2): 83-7. [http://dx.doi.org/10.4103/jioh.jioh_6_18]

[16] Ibrahim NK, Alwafi HA, Sangoof SO, Turkistani AK, Alattas BM. Cross-infection and infection control in dentistry: Knowledge, attitude and practice of patients attended dental clinics in King Abdulaziz University Hospital, Jeddah, Saudi Arabia. J Infect Public Health 2017; 10(4): 438-45.

[http://dx.doi.org/10.1016/j.jiph.2016.06.002] [PMID: 27422140]

[17] Halboub ES, Al-Maweri SA, Al-Jamaei AA, Tarakji B, Al-Soneidar WA. Knowledge, attitudes, and practice of infection control among dental students at Sana'a University, Yemen. J Int Oral Health 2015; 7(5): 15-9.

[PMID: 26028896]

[18] Bellissimo-Rodrigues WT, Bellissimo-Rodrigues F, Machado AA. Infection control practices among a cohort of Brazilian dentists. Int Dent J 2009; 59(1): 53-8. [PMID: 19323312]

[19] Pavarina AC, Pizzolitto AC, Machado AL, Vergani CE, Giampaolo ET. An infection control protocol: effectiveness of immersion solutions to reduce the microbial growth on dental prostheses. J Oral Rehabil 2003; 30(5): 532-6.

[http://dx.doi.org/10.1046/j.1365-2842.2003.01093.x] [PMID: 12752936]

[20] Salvia ACRD, Matilde FdosS, Rosa FCS, et al. Disinfection protocols to prevent cross-contamination between dental offices and prosthetic laboratories. J Infect Public Health 2013; 6(5): 377-82.

[http://dx.doi.org/10.1016/j.jiph.2013.04.011] [PMID: 23999338]

[21] Sivakumar I, Arunachalam KS, Solomon E. Occupational health hazards in a prosthodontic practice: review of risk factors and management strategies. J Adv Prosthodont 2012; 4(4): 259-65. [http://dx.doi.org/10.4047/jap.2012.4.4.259] [PMID: 23236581]

[22] Vázquez-Rodríguez I, Estany-Gestal A, Seoane-Romero J, Mora MJ, Varela-Centelles P, Santana-Mora U. Quality of cross-infection control in dental laboratories. A critical systematic review. Int J Qual Health Care 2018; 30(7): 496-507.

[http://dx.doi.org/10.1093/intqhc/mzy058] [PMID: 29635417]

[23] Deogade SC, Suresan V, Galav A, Rathod J, Mantri SS, Patil SM. Awareness, knowledge, and attitude of dental students toward infection control in prosthodontic clinic of a dental school in India. Niger J Clin Pract 2018; 21(5): 553-9.

[http://dx.doi.org/10.4103/njcp.njcp_81_17] [PMID: 29735853]

[24] Alshiddi IF. Attitude and awareness of dental students and interns toward infection control measures in prosthodontic clinics. J Int Oral Health 2015; 7(12): 10-5.

[25] Osman T. Epidemiology of sharp instruments injuries at a dental school in Sudan. Int J Infect Control 2014; 10(4): 10.3396. [http://dx.doi.org/10.3396/ijic.v10i4.030.14]

[26] Binalrimal S, AlDrees A, AlWehaibi M, et al. Awareness and compliance of dental students and interns toward infection control at Riyadh Elm University. GMS Hyg Infect Control 2019; 14: Doc10. [PMID: 31538043]

[27] Rahman B, Abraham SB, Alsalami AM, Alkhaja FE, Najem SI. Attitudes and practices of infection control among senior dental students at college of dentistry, university of Sharjah in the United Arab Emirates. Eur J Dent 2013; 7(Suppl. 1): S015-9. [http://dx.doi.org/10.4103/1305-7456.119058] [PMID: 24966723]

[28] Nelson AL. Safe patient handling and movement: A guide for nurses and other health care providers. New York, NY: Springer Publishing Company 2006.

[29] Shah K, Koka S. Evidence-based practice and barriers to compliance: Face bow transfer. J Prosthodont Res 2016; 60(1): 20-2.

[http://dx.doi.org/10.1016/j.jpor.2015.09.004] [PMID: 26481058]

[30] Gilmour AS, Welply A, Cowpe JG, Bullock AD, Jones RJ. The undergraduate preparation of dentists: Confidence levels of final year dental students at the School of Dentistry in Cardiff. Br Dent J 2016; 221(6): 349-54.

[http://dx.doi.org/10.1038/sj.bdj.2016.686] [PMID: 27659639]

[31] Keat RM, Sheik SA, Thomas M, Albuquerque R, Hill K. A crosssectional study of confidence in minor surgical skills amongst junior dentists. Eur J Dent Educ 2018; 22(3): e379-85.

[http://dx.doi.org/10.1111/eje.12314] [PMID: 29316092]

[32] Al-Shamiri HM, AlShalawi FE, AlJumah TM, AlHarthi MM, AlAli EM, AlHarthi HM. Knowledge, attitude and practice of hepatitis B virus infection among dental students and interns in Saudi Arabia. J Clin Exp Dent 2018; 10(1): e54-60. [PMID: 29670716]

[33] Balcos C, Barlean MC, Bobu L, Popescu E. Evaluation of infection control knowledge and attitudes among dental technicians in Iasi. 
Romanian Journal of Oral Rehabilitation 2018; 10(1): 120-7.

[34] Wu F, Zhao S, Yu B, et al. A new coronavirus associated with human respiratory disease in China. Nature 2020; 579(7798): 265-9. [http://dx.doi.org/10.1038/s41586-020-2008-3] [PMID: 32015508]

\section{(C) 2020 Halawaniet al.}

This is an open access article distributed under the terms of the Creative Commons Attribution 4.0 International Public License (CC-BY 4.0), a copy of which is available at: (https://creativecommons.org/licenses/by/4.0/legalcode). This license permits unrestricted use, distribution, and reproduction in any medium, provided the original author and source are credited. 